\title{
\#UsToo: implicit bias, meritocracy and the plight of black minority leaders in healthcare
}

\author{
Jamiu 0 Busari (i) 1,2
}

${ }^{1}$ Faculty of Health, Medicine and Life Sciences, Maastricht University, Maastricht, The Netherlands

2Pediatrics, Zuyderland Medical Center, Heerlen, The Netherlands

\section{Correspondence to} Dr Jamiu O Busari, Faculty of Health, Medicine and Life Sciences, Maastricht University, Maastricht, The Netherlands; jamiu.busari@

maastrichtuniversity.n

Received 18 May 2019

Accepted 1 September 2019

Published Online First

11 October 2019

\section{ABSTRACT}

In the fall of 2017, the \#MeToo movement ushered in one of the most astonishing revolts against the perils of workplace-related harassment. Several unsuccessful campaigns geared towards ending the harassment and subjugation of women in corporate organisations finally got a thrust that resulted in significant and far-reaching changes in many organisations. While the \#MeToo movement highlighted the pains and struggles of gender inequality over the years, an unintended consequence has been the shadow it has cast over the plight of other minority groups facing harassment in the workplace. In several academic and healthcare (learning) environments, people of colour, like women, face explicit and implicit forms of harassment on a regular, if not daily basis. Unlike gender harassment, however, racial harassment affects both sexes with relatively more predominance among men. The effect of racial harassments does not just impact performance and self-confidence but also influences the opportunities available to black professionals to advance their academic and professional careers. In the academic and healthcare industries, the issue of how to tackle implicit bias and unfair practices is not clear-cut. While the subjugated feel the impact of bias, the perpetrators of the actions either lack the ability (or are unwilling) to acknowledge these biases. Furthermore, the complexities inherent to the different contexts make it problematic if not impossible, to call out racist behaviours. In this paper, a real-life case scenario is used to provide a scholarly analysis of the dynamics of racial harassment, implicit bias and the impact on minority leader roles in healthcare delivery.

\section{INTRODUCTION}

In the Autumn of 2017, the \#MeToo movement hit the spotlights and along with it came a major revolt that changed the culture of harassment against women in the workplace. ${ }^{1}$ What initially began as an alteration against powerful forces in the entertainment industry quickly gained momentum and spread to include other industries such as the media, politics and sports. Through the \#MeToo movement, women found a new voice to point out harassment in the workplace, forcing companies and society to take the issue more seriously. As a result, more than 200 prominent men lost their jobs to the crusade and nearly half of them were succeeded by women. ${ }^{1}$ Some things we have learnt from the \#MeToo movement is the enormity of sexual harassment in the workplace, the emotional and psychological impact it has (had) on its victims and that the problem of sexual harassment is not limited to a specific industry. We have also learnt that not only women are victims of sexual harassment, and that the impact of \#MeToo is still reverberating in other domains, as we see more cases of harassment being linked to religious, academic and healthcare institutions.

In many academic and medical learning environments, people of colour (be they faculty or trainees) encounter harassment regularly, if not daily. These harassments could be overt and direct (eg, physical or verbal harassment) or they can be concealed (eg, implicit bias and psychological intimidation). Regardless of their nature, however, the impact of harassment on personal performance and selfconfidence adds more strain to the pre-existent challenges that people of colour face, both in their academic and professional lives. ${ }^{2}$ Not too long ago, Darrel G Kirch, President of the AAMC wrote an opinion piece on LinkedIn and shed light on the psychological and professional costs of racism in American healthcare and academic systems. ${ }^{3}$ In his eloquently crafted opinion piece, Kirch skilfully drew the reader's attention to the "elephant in the room", articulating the problem of racial bias in academic medicine and highlighting the costs of (implicit) bias on the professional development of people of colour. ${ }^{4}$ In so doing, he revived the discussion about the way we ought to be interacting with each other as human beings, regardless of race, religion, sexual orientation, gender, (dis)ability or age in academia and healthcare delivery.

\section{THE CASE OF DR BROWN}

Dr Brown (not his real identity) is a respected clinician and academic with acclaimed leadership competencies. He recently applied for a leadership position in a teaching hospital and was one of the candidates that made it to the last stage of a rigorous selection process. As part of the selection procedure, Dr Brown underwent an executive matching assessment and received an unequivocal and positive recommendation by the executive matching firm for the job he was applying for. In addition to being considered competent for the job, the assessment showed that he had a healthy balance between his 'people-oriented' and 'taskoriented' competencies. 'People oriented' as used in this context referred to his capacity to demonstrate compassion and be empathetic with others. Unfortunately, as things turned out, Dr Brown did not get the job although the search committee did acknowledge that he was a suitable candidate for the position and possessed the required competencies needed for the job. The reason why Dr Brown was not offered the job, however, was because the search committee felt that his strong 'peopleoriented' profile posed a risk to the position he was applying for. The search committee told him that 
they were looking for a directive and more task-oriented candidate, which meant that his compassionate and empathetic leadership style was not a good match for the position and for the team the search committee was putting together.

To the reader, it is understandable that Dr Brown was disappointed when he found out that he did not get the job. Especially, when we place it into the context that he was specifically cultivating his people-oriented skills to improve his capability as a healthcare leader and prepare himself for a role similar to the one he was applying for. What makes the narrative interesting, however, was the reason the search committee gave to support their decision not to offer Dr Brown the job, that is, their preference for a candidate with a directive and indifferent leadership style for the leadership position. While this explanation was seemingly admissible to the search committee, in the current era of value-based healthcare practices, it was not the sort of explanation expected to be used to rationalise leadership building at the top of a healthcare organisation. ${ }^{5}$ Furthermore, the evidence in the literature shows that individuals with demonstrable compassion, empathy, and excellent communications skills are those whom we should be recruiting to lead our healthcare organisations. ${ }^{6}$

\section{COGNITIVE DISSONANCE AND IMPLICIT BIAS}

So, what is the reason for sharing Dr Brown's story? The purpose of sharing this narrative is not because Dr Brown failed to get the job, but rather about the 'cognitive dissonance' of trying to understand why he did not get the job. To refresh our memory, cognitive dissonance is that state of mental distress that a person experiences when confronted with two or more contradictory beliefs, ideas or values. The discomfort of cognitive dissonance arises when we face situations where previously held beliefs clash with new evidence that is presented to us and then we are forced to search for a way to resolve the contradiction and reduce the mental discomfort. In the case of Dr Brown's interview, his being disqualified for a healthcare leadership position because he was 'people-oriented' and less directive triggers a cognitive dissonance that does not resonate with the core values of what it is to be a healthcare provider or leader for that matter. Especially, when we link this to the current evidence in healthcare leadership where compassion, emotional intelligence and good communication skills are considered to be essential competencies that every effective healthcare leader should possess. ${ }^{67}$

For the reasons described above and the collective understanding that compassionate and emotionally intelligent leaders are needed in our healthcare systems, disqualifying a candidate based on 'people-oriented' qualities do not make sense. Moreover, in Dr Brown's case, a 'logical' explanation for why he was not offered the job after being cleared to be a suitable candidate remains wanting. This leaves the observer with questions about what the real reason could have been, not to offer Dr Brown the job. If we now expand the story to include the fact that Dr Brown was from an ethnic minority group (black), one may then wonder if his ethnicity could have been an underlying reason for not being offered the job (i.e., implicit bias). Worldwide and in several corporate organisations, ethnic minorities are generally underrepresented in top executive positions. ${ }^{89}$ For this group of professionals, it is known that they are regularly exposed to different types of implicit and open biases in their work and also, when applying for promotion or seeking new jobs. ${ }^{10} 11$ Anecdotal experiences show that in situations where black minorities fail to secure a new job or a request for promotion, the explanation they receive is often vague and barely justifies the credibility of the unfavourable outcome. This in turn fails to eliminate any perceived implicit racial bias or ulterior political motive. ${ }^{12}$

In Dr Brown's case, besides his ethnicity, one may wonder despite being cleared by the executive matching firm, if there were other issues that may have influenced the outcome the interview. For example, whether there were issues other than implicit bias that he probably was unaware of and which the search committee was unable or unwilling to share with him. One may also argue whether it was okay for the search committee to decide against his selection following the strongly favourable recommendation of the matching firm. In the same light, if the committee did decide to disregard the executive matching firm's recommendation, then they should also have been prepared (and willing) to authentically describe the reason for doing so to the candidate. The question though, is who should be privy to this explanation, and do they owe this to the candidate? Ultimately, for Dr Brown, there was no satisfactory explanation to quell the nagging question he had about the outcome of the procedure. The question he kept asking himself was 'would I have got the job (with the same academic and professional credentials and the same positive assessment from the executive matching firm) if I were white?'.11

Now, while the \#MeToo movement highlights decades of pain associated with the struggles for gender equality in our societies, an unintended consequence of this breakthrough is that the plight of other minority groups, for example, ethnic minorities facing harassment in the workplace may be (unintentionally) overshadowed. ${ }^{13-15}$ Furthermore, racial harassment unlike the harassment of women, affects both sexes with relatively more predominance among men. ${ }^{9}$ Still, within this line of thinking, we can argue that the insurgence of \#MeToo has also brought in its wake, a revival to fight discrimination and the implicit biases meted out to all minority groups in general. ${ }^{16}{ }^{17}$ Although a lot has been learnt from the rise of the \#MeToo movement, the issue of how to tackle implicit bias and unfair practices in academic medicine is still difficult and unclear. While the recipients of implicit bias feel its impact, the perpetrators of such prejudices lack the ability or willingness to recognise, let alone acknowledge their actions. Furthermore, the complexities inherent to the different contexts make it problematic if not impossible to call out racist behaviours, especially when the person calling it out is the subject at the receiving end.

To support individuals who are hurt, put down, marginalised and abused by bias, we need to recognise the consequences of these biases to them and the patients they serve. We also have to realise that there is a price to pay for racism and the unfair practices associated with it. This price includes the perpetuation of behaviours that do not align with the principles of a just culture and the marginalisation of particular groups within society. It means that there would be a poor representation of ethnic minorities in academic and healthcare sectors and a potential loss of highly qualified individuals from positions where they can contribute meaningfully to the system. ${ }^{9} 13$ There would also be a loss of diversity in the composition of teams and in the innovation that different individuals inject into academic and healthcare systems. ${ }^{13}$ On a personal level, there is the psychological stress that it will cost individual practitioners of colour. Therefore, like the \#MeToo movement, we need to address the 'elephant in the room' regarding racism in our academic and healthcare institutions. We need to recognise and acknowledge the impact of implicit bias on black academics and healthcare professionals (in leadership positions).

As a clinician, educator and healthcare leader, I hold the firm belief that the foundation of exemplary leadership lies in our 
ability to demonstrate compassion and empathy. The evidence in the leadership literature supports this, showing that leaders who are compassionate, who have excellent communication skills and who demonstrate high emotional intelligence are very successful and are often the most effective leaders. ${ }^{71819}$ The medical education literature also shows that compassionate and empathetic clinicians with excellent communication skills are often the ones that learners tend to associate with and regard as exemplary role models. ${ }^{2021}$

\section{CONCLUSION}

Although the awareness of racism exists in many organisations, the actions being taken to bridge the divide in terms of opportunities for growth and participation are still insufficient. A few actions that can be taken to start the conversation however include embracing the lessons from the way women in academia and healthcare have tackled the imbalance. We can recruit experiences from the \#MeToo movement to support the plight of black minorities (\#UsToo) who are aspiring for promotion or leadership roles through coaching. We need to create a 'just' community of practice, where unbiased meritocracy forms the motor that drives selection of candidates for academic promotion and job appointments. Healthcare systems need to recruit more compassionate leaders with the capacity to serve their constituencies humbly and lead their teams with their hearts and heads (humble leadership).

Moving forward, we need a community of practice that embraces meritocracy and inclusiveness and ensures a just culture of practice. As healthcare leaders, we need to embrace 'leading with compassion' unflinchingly, knowing that it would always get us the results that will stand the test of time. Finally, for the benefit of all, we need to acknowledge the mechanisms of implicit bias and find ways to prevent the potential harm it causes our patients and care providers.

Acknowledgements The author wishes to thank Professor Deepak Dath (McMaster University, Hamilton, California, USA) for critically reviewing and providing helpful suggestions to the initial draft of this manuscript.

Contributors JB actively contributed to the conception, design, writing and critical review of this manuscript before submission. All those listed as authors qualify for authorship.

Funding The authors have not declared a specific grant for this research from any funding agency in the public, commercial or not-for-profit sectors.

Disclaimer This paper has not been published or submitted elsewhere.

Competing interests None declared.
Patient consent for publication Not required.

Provenance and peer review Not commissioned; externally peer reviewed.

\section{ORCID iD}

Jamiu O Busari http://orcid.org/0000-0002-8616-5564

\section{REFERENCES}

1 Carlsen A, Salam M, Miller CC. \#MeToo Brought Down 201 Powerful Men. Nearly Half of Their Replacements Are Women. New York Times, 2018. Available: https://www. nytimes.com/interactive/2018/10/23/us/metoo-replacements.html [Accessed 16 Jul 2019].

2 Bernard DL, Hoggard LS, Neblett EW, et al. Racial discrimination, racial identity, and impostor phenomenon: a profile approach. Cultur Divers Ethnic Minor Psychol 2018:24:51-61.

3 Kirch DG. Addressing racism and mistreatment in academic medicine: Linkedln, 2019. Available: https://www.linkedin.com/pulse/addressing-racism-mistreatment-academic medicine-kirch-m-d-/ [Accessed 17 May 2019].

4 Chapman EN, Kaatz A, Carnes M. Physicians and implicit bias: how doctors may unwittingly perpetuate health care disparities. J Gen Intern Med 2013;28:1504-10.

5 Porter ME. What is value in health care? N Engl J Med 2010;363:2477-81.

6 Wedge J. Unique qualities define successful healthcare leaders. Healthc Pap 2003;4:75-7. discussion 88-90.

7 Giles $\mathrm{S}$. The most important leadership competencies, according to leaders around the world. Harvard Business Review, 2016.

8 Roberts LM, Mayo AJ, Ely RJ. Beating the odds. Harvard Business Review, 2018.

9 Thomas DA, Gabarro JJ. Breaking through: the making of minority executives in corporate America. First ed. Harvard Business School, 1999.

10 Thomas DA. The truth about mentoring minorities: race matters. Harvard Business Review, 2001.

11 Bell ELJ, Nkomo SM. Our separate ways: black and white women and the struggle for professional identity. Harvard Business School, 2003.

12 Gündemir S, Homan AC, de Dreu CKW, et al. Think leader, think white? capturing and weakening an implicit Pro-White leadership bias. PLoS One 2014;9:e83915.

13 McGirt E, black Lwhile. An inside look at what's keeping black men out of the executive suite. Fortune 2016 https://fortune.com/longform/black-executives-men-csuite/ (Accessed 16 July, 2019).

14 Snipp CM, Cheung SY. Changes in racial and gender inequality since 1970. Ann Am Acad Pol Soc Sci 2016;663:80-98.

15 Tomaskovic-Devey D, Roscigno VJ. Racial economic Subordination and white gain in the U.S. South. Am Sociol Rev 1996:61:565-89.

16 Perry BL, Harp KLH, Oser CB. Racial and gender discrimination in the stress process: implications for African American women's health and well-being. Sociol Perspect 2013;56:25-48.

17 Thomas M, Moye R, Race MR. Race, class, and gender and the impact of racial segregation on Black-White income inequality. Sociol Race Ethn 2015;1:490-502.

18 Collins J. Level 5 leadership: the triumph of humility and Fierce resolve. Harvard Business Review, 2005: 1-13.

19 Segal J. Good leaders use "emotional intelligence". Emotionally intelligent leadership is a skill that can be learned and taught throughout life. Health Prog 2002;83:44-6. 66.

20 Buchel TL, Edwards FD. Characteristics of effective clinical teachers. Fam Med 2005;37:30-5

21 Masunaga $\mathrm{H}$, Hitchcock MA. Residents' and faculty's beliefs about the ideal clinical teacher. Fam Med 2010;42:116-20. 